\title{
Um estudo sobre escolas eficazes no Brasil e na Itália: o que realmente importa na opinião dos pais, alunos, professores e gestores
}

\author{
Effective schools: what really matters in the opinion of parents, students, \\ teachers and principals?
}

Las escuelas eficaces: lo que realmente importa en la opinión de los padres,
estudiantes, maestros y administradores

PAUlo SÉRgIo Garcia*

NELIO BIZZO**

\begin{abstract}
$\diamond$
RESUMO

Este estudo investiga os fatores escolares que explicam o desempenho acadêmico dos estudantes sob a visão dos grupos envolvidos no processo de formação: família, alunos, professores e gestores. Um estudo de caso, coletando dados por meio de entrevistas, foi realizado em duas escolas, uma no Brasil e outra na Itália, onde seus alunos apresentaram alto rendimento acadêmico. Os resultados revelaram que não há um fator isolado que explique o desempenho e, sim, múltiplos fatores, formando um campo magnético que sustenta e apoia a aprendizagem e o rendimento dos estudantes. Doze fatores na realidade brasileira e 11 na italiana foram citados por todos os grupos como explicativos do alto desempenho, sendo o principal fator o professor. Esses dados são relevantes para os especialistas, que podem utilizá-los em formação inicial e continuada, mas, sobretudo, para os gestores, utilizando-os na melhoria de suas escolas.
\end{abstract}

Palavras-chave: Melhoria das escolas. Desempenho dos alunos. Fatores escolares.

\begin{abstract}
This study investigates the school factors that explain students' achievement under the perspective of the groups that are involved in the teaching and learning process: families, students, teachers and principals. A case study, collecting data through interviews was conducted in two schools, one in Brazil and another in Italy, where its students achieved high academic achievement. The results showed that it was not found a single factor explaining student performance. Twelve factors in Brazilian reality and eight in the Italian were found. Teacher was considered the main factor that influenced student. These data can be used by universities professors in pre and in-service education to promote discussion about school quality, and can be also used by principals in their schools as a way of better organizing the school.
\end{abstract}

Keywords: School improvement. Students' performance. School factors.

\section{RESUMEN}

Este estudio investiga los factores escolares que explican el rendimiento académico de los estudiantes bajo la visión de los grupos que participan en el proceso de formación: la familia, los estudiantes, maestros y administradores. Un estudio de caso, la recogida de datos a través de las entrevistas se realizó en dos escuelas, una en Brasil y otra en Italia, donde sus estudiantes tenían un alto rendimiento académico. Los resultados mostraron que no existe un único factor que explica el rendimiento, sino una pluralidad de factores, formando un campo magnético que sostiene y apoya el aprendizaje y el rendimiento académico. Doce factores en la realidad brasileña y las once de la italiana fueron citados por todos los grupos como explicativo de alto rendimiento, siendo el principal factor el maestro. Estos datos son relevantes para los expertos que pueden utilizarlos en la educación inicial y continua, pero especialmente a los gestores de trabajo para mejorar sus escuelas.

Palabras clave: Mejora de las escuelas. El desempeño del estudiante. Factores escolares.

\footnotetext{
* Doutor e Pós-doutorado na Faculdade de Educação da Universidade de São Paulo, professor dos cursos de mestrado da Universidade Municipal de São Caetano do Sul e Coordenador do Observatório de Educação do Grande ABC. E-mail: <paulo.garcia@uscs.edu.br>.

**Professor Doutor e Livre-docente na Faculdade de Educação da Universidade de São Paulo, professor dos cursos de mestrado e doutorado da Feusp. E-mail: <bizzo@usp.br>.
} 


\section{INTRODUÇÃO}

Estudos mais antigos, realizados nos Estados Unidos (COLEMAN, 1966), na França (SAUVY; GIRARD, 1965; CRESAS, 1978) e na Inglaterra (DOUGLAS; ROSS; SIMPSON, 1968), e mais recentes (CRAHAY; BAYE, 2013) já tinham mostrado que o nível socioeconômico e a formação dos pais são os principais fatores que afetam o desempenho dos alunos. Tais estudos sinalizaram que crianças com menor nível socioeconômico, menor renda, em que normalmente os pais têm baixa escolaridade, apresentam desempenho menor e atingem com menos frequência níveis mais altos na trajetória escolar. Situação diferente daqueles cuja renda familiar é mais alta e os pais possuem algum tipo de profissão liberal/intelectual.

Outro estudo (OCDE, 2011) permite compreender a universalidade de tal fenômeno, quando afirma que a condição social, econômica e cultural dos pais explica em grande medida as competências e aquisições dos alunos. Crahay e Baye, (2013, p. 878) afirmaram que em todas as nações que participaram ao menos uma vez de algum estudo internacional o mesmo fenômeno foi constatado e que "o sucesso escolar é, portanto, ainda hoje, o campo de um determinismo social gerador de desigualdades, o que autoriza a concluir que não existe em nenhum lugar uma escola plenamente justa e eficaz".

Além dos aspectos socioeconômicos e da formação dos pais, fatores escolares também determinam o desempenho dos alunos. Entre as várias pesquisas internacionais, Willms (1992) identificou fatores que influenciavam a eficácia escolar. Entre eles estavam aqueles em relação à escola: ecologia e meio (infraestrutura, características dos gestores/professores e composição dos alunos); segregação (grau de separação dos alunos, status socioeconômico); clima disciplinar; ênfase acadêmica; aqueles em associados aos alunos (atitudes em relação à escola e ao professor); e outros ligados aos professores (compromisso moral, condições de trabalho, autonomia). Lee, Bryk e Smith (1993) realizaram uma revisão da literatura sobre a organização nas escolas que apresentavam bons resultados, propondo um modelo conceitual baseado em fatores externos e internos relacionadas aos professores e aos alunos. No mesmo sentido, Sammons, Hillman e Mortimore (1995) identificaram 11 fatores interdependentes relacionados às características das escolas eficazes: liderança profissional, objetivos e visões compartilhadas, ambiente de aprendizagem, concentração no ensino e na aprendizagem, ensino e objetivos claros, altas expectativas, incentivo positivo, monitoramento do progresso do aluno, direitos e responsabilidades do jovem, parceria casa-escola e uma organização orientada à aprendizagem.

Meuret (2000), na França, mostrou que quanto mais eficazes eram as escolas menos seletivas elas eram em relação aos alunos. A eficácia foi traduzida na melhoria do rendimento dos estudantes mais fracos, nos métodos pedagógicos e nos professores que aproveitavam ao máximo o tempo para a aprendizagem. Para Scheerens e Bosker (1997) e Scheerens (2000), os fatores que fazem a diferença estão relacionados à liderança educacional, traduzida pela capacidade de mobilização dos líderes no contexto escolar; ao consenso e à coesão da equipe escolar, traduzidos nos tipos e frequência das reuniões, formas e satisfação em face da cooperação, nos indicadores da cooperação bem-sucedida; ao clima escolar, manifestado por uma atmosfera de ordem, normas, sanções e recompensas; ao baixo absenteísmo e evasão; à ênfase na avaliação, no monitoramento do progresso dos alunos, usando resultados; ao envolvimento dos pais na vida escolar de seus filhos.

Casassus (2002) revelou que um dos fatores mais relevantes do aproveitamento discente foi o clima favorável à aprendizagem, traduzido como situações de bom convívio entre os jovens e poucas ocorrências de violência. No Chile, Mella et al. (2002) relacionaram vários fatores relevantes sobre o clima escolar em escolas bem-sucedidas: respeito às ideias e apreciações dos professores; compromisso e vocação dos docentes; liderança pessoal; apoio individual ao aluno; cooperação e divisão das responsabilidades; tratamento pessoal adequado; baixa rotatividade dos professores e altas expectativas em relação aos alunos. Raczynski e Muñoz (2003) avaliaram os fatores que levaram escolas pobres do Chile a apresentarem bom desempenho nas avaliações nacionais, classificando-os em fatores em nível da escola e da sala de aula.

No Brasil, os estudos têm utilizado dados oficiais (Censos, Saeb, Pesquisa Nacional por Amostra de Domicílios) e informações do fluxo escolar e do desempenho dos alunos. Neste sentido, eles contribuíram para a compreensão da realidade brasileira, sobretudo aquela relativa ao Ensino Fundamental nas áreas de Português e Matemática. Franco e Bonamino (2005) investigaram os fatores escolares associados à eficácia escolar e agruparam em cinco categorias: recursos escolares, organização e gestão da escola, clima acadêmico, formação e salário docente e ênfase pedagógica.

Em relação à infraestrutura (IE), recursos escolares, equipamentos e prédio escolar e conservação, o estudo de Castro e Fletcher (1986) foi um dos primeiros a mostrar sua importância para a aprendizagem, identificando a precária situação das instalações físicas e a pouca quantidade de equipamentos disponíveis para a realização das atividades pedagógicas. Dados baseados no Saeb 2001，8 ${ }^{\text {a }}$ série (SOARES; MAMBRINI; PEREIRA; ALVES, 2001; LEE; FRANCO; ALBERNAZ, 2004), mostraram os efeitos positivos da IE em relação ao 
desempenho dos alunos que participaram do Pisa 2000. Espósito, Davis e Nunes, (2000) demonstraram que as condições de funcionamento dos laboratórios e dos espaços para atividades pedagógicas fazem diferença na aprendizagem dos jovens. Sátyro e Soares (2007) analisaram as condições da IE das escolas do Ensino Fundamental, com base nos dados dos Censos Escolares de 1997 a 2005, mostrando que aconteceram melhorias na IE, nesse período, que, no entanto, não incidiram sobre a repetência e sobre o aprendizado dos alunos.

Medindo a IE por meio de uma escala, Soares Neto et al. (2013) mostraram que, aproximadamente, 84,5\% (164.786) das escolas situavam-se no nível Elementar ou Básico (45\% nível Elementar, 86.739; 40\% no Básico, 78.047). Desse total, somente $14,9 \%$ se encontravam no plano Adequado (29.026) e 0,6 no Avançado (1.120).

Quanto à organização e à gestão da escola, Franco, Albernaz e Ortigão (2007) e Soares e Alves (2003) mostraram que o reconhecimento da liderança do diretor pelos professores é uma característica associada à eficácia escolar. Soares, Mambrini, Pereira e Alves (2001) destacaram a dedicação do diretor, sua atuação, formas de conduzir o grupo e a capacidade de criação como fatores essenciais para o desenvolvimento escolar. Espósito, Davis e Nunes (2000) e Lee, Franco e Albernaz (2004) mostraram que a responsabilidade coletiva e o trabalho colaborativo tinham efeitos positivos sobre os resultados dos alunos. A colaboração constitui uma importante ferramenta para o desenvolvimento docente, para a valorização das pessoas, para o compartilhamento do conhecimento e para reduzir a sensação de impotência, aumentando a eficiência do trabalho.

No clima acadêmico, a ênfase está em ensino e aprendizagem, em valorização de resultados acadêmicos e altas expectativas em relação aos alunos por parte dos professores. Pesquisadores demonstraram que corrigir o dever de casa tinha efeitos nos resultados dos alunos (FRANCO; ALBERNAZ; ORTIGÃO, 2007; MACHADO SOARES, 2004). Machado Soares (2004) mostrou o efeito positivo relacionado ao interesse, à dedicação, à disponibilidade e ao nível de exigência (passar mais dever de casa) do professor sobre o desempenho médio das escolas. Lee, Franco e Albernaz (2004) também reportaram a exigência docente como uma categoria que tem efeitos na aprendizagem. $\mathrm{O}$ baixo índice de absenteísmo foi citado por Machado Soares (2004) e Lee, Franco e Albernaz (2004) como impactante sobre a eficácia e sobre a equidade escolar. Schiefelvein e Simmons (1980) e Castro et al. (1984) revelaram que a maximização do uso tempo de aprendizagem, incluindo o prolongamento por meio do dever de casa, foi um fator que impactou a aprendizagem e o rendimento dos alunos.
Quanto à formação e ao salário docente, não há muitos estudos na realidade brasileira, e a intensidade desses efeitos também é menor. Albernaz, Ferreira e Franco (2002), utilizando dados do Saeb de 1999, mostraram efeito positivo sobre a eficácia escolar na categoria nível de formação docente e salário do professor.

Klein e Fontanive (2010) e Scartezini e Viana (2012, p. 03) afirmaram que o fator mais relevante no desempenho dos alunos é o professor, e que ainda não se conhece detalhadamente como sua prática impacta a aprendizagem. Para os autores, o comportamento docente é determinante nos resultados das turmas, sendo preciso identificar e estudar melhor este efeito denominado professor. Fernandes et al. (2010, p. 569) revelaram que quando os professores têm conhecimento sobre os processos de avaliação em larga escala seus alunos apresentam maior desempenho. Gomes (2005, p. 239) mostrou que os atributos dos bons professores "são precisamente aqueles que escapam aos critérios burocráticos de recompensas em suas carreiras, de tal modo que continua de pé a questão de como selecionar, gratificar e promover os melhores em detrimento dos piores". Paul e Barbosa (2008) retrataram as correlações entre a qualidade docente e a eficácia escolar e discutiram políticas educacionais em relação à eficiência e à equidade, mostrando que a experiência do professor e a baixa rotatividade nas escolas influenciavam positivamente a aprendizagem dos alunos.

Por fim, a ênfase pedagógica é pouco discutida na escola para o planejamento ou Projeto Político Pedagógico. Dessa forma, há na escola diferentes ênfases, que, no entanto, podem ser agrupadas em duas: tradicionais e progressistas. Cada professor utiliza sua abordagem sem, na maioria das vezes, nenhum tipo de acompanhamento da gestão escolar. Os estudos mostraram resultados impactantes no ensino orientado pela reforma da Educação Matemática (FRANCO; SZTAJN; ORTIGÃO, 2004). Nesse caso, raciocínios de alta ordem e resolução de problemas contextualizados. Outros pesquisadores (SOARES; MAMBRINI, PEREIRA; ALVES, 2001) demonstraram impactos positivos associados à utilização de métodos ativos de ensino.

Pelas características desse tipo de investigação, a grande maioria desses estudos no Brasil está assentada na metodologia quantitativa e baseada em dados do Censo Escolar e do Saeb. No entanto, outra alternativa viável é a utilização de métodos qualitativos, com foco naqueles que participam do processo de ensino e aprendizagem, para analisar uma realidade que escapa à investigação estatística. Este estudo, a fim de preencher essa lacuna, investiga os fatores escolares que explicam o bom desempenho acadêmico dos alunos, a partir da visão dos grupos que estão envolvidos no processo de ensino e aprendizagem: família, alunos, professores e gestores. 
Os dados e a identificação dos fatores que explicam o desempenho acadêmico dos alunos, a partir da perspectiva daqueles que estão envolvidos no processo de formação, vão permitir a construção de teorias subjetivas com o intuito de melhorar a escola e o rendimento dos alunos e, ao mesmo tempo, sustentarão e apoiarão futuras investigações mais detalhadas sobre como esses fatores funcionam, como influenciam os estudantes e como se comportam em termos de intensidade na escola e na sala de aula.

\section{O OBJETO DE ESTUDO}

O sistema de educação brasileiro está organizado e estruturado de acordo com a Lei de Diretrizes da Educação Nacional (LDBEN/96), que estabeleceu sua finalidade, sua organização e a responsabilidade dos órgãos administrativos. Em nível federal, os órgãos responsáveis pela Educação são o Ministério da Educação e o Conselho Nacional de Educação. O sistema é composto de níveis, Educação Básica e Superior, e modalidades, Educação Especial, de Jovens e Adultos, Profissional e a Distância (art. 21, LDBEN/96).

Segundo o Censo da Educação Básica de 2015, a situação da educação brasileira revela que existem um pouco mais de 183 mil escolas de Educação Básica, com cerca de 50 milhões alunos matriculados. Neste contexto, perto de $80 \%$ estão em escolas públicas. A esfera municipal abriga, aproximadamente, $62 \%$ das matrículas.

O sistema escolar italiano é formado pelo Dipartimento per l'istruzione, per l'università, l'alta formazione artistica, musicale e coreutica e per la ricerca e per la programmazione e la gestione delle risorse umane, finanziarie e strumentali (Ministero, 2014). Este se divide em Escola da Infância, Primária, Secundária, Ensino Superior, Educação Profissional e Técnica Superior. A duração da escola infantil é de cinco anos, mas a escolaridade obrigatória é de nove anos (6 aos 15 anos), prevendo cinco anos de Escola Primária, três de primeiro ciclo da Secundária (média inferior) e um ano de segundo ciclo (Escola Média Superior). No fim dessa fase, é realizado um exame para a obtenção do diploma de Escola Primária e Média. A Escola Secundária (ES) é formada por dois ciclos (Scuola Secondaria di I Grado com duração de três anos - dos 11 aos 13/14 anos e Scuola Secondaria Superiore dos 14 aos 18/19 anos). Esta apresenta dois percursos: o sistema de Liceus e o percurso do ensino-formação profissional. Após a finalização do curso no Liceu há um exame de Estado para acessar as universidades (Esame di Maturità).

No ano de 2013/2014, havia 8.644 escolas na Itália. A região da Campania e da Lombardia eram aquelas que abrigavam o maior número de unidades: 1.030 e 1.149 , respectivamente. Existiam quase 8 milhões de alunos, com cerca de 2 milhões e 500 mil na escola primária.

As escolas investigadas estão localizadas na Itália, na cidade de Vicenza, região do Veneto (Escola A) e a outra no Brasil, na região do ABC Paulista (Escola B). Estas, de Ensino Médio (Secundário), foram selecionadas porque apresentaram bons resultados nos exames nacionais e eram consideradas de qualidade pela comunidade, gestores, alunos e professores.

A escola A obteve bons resultados no exame nacional (Instituto Nacional de Avaliação do Sistema Educativo). Tal exame ocorre no terceiro ano do Ensino Secundário. Em 2011, a escola obteve a média 86,9 em Italiano e 75,4 em Matemática. As escolas italianas obtiveram 78,3 e 53,3 e da região do Veneto, 81,9 e 57,0, respectivamente. O nível socioeconômico médio da escola era médio e alto.

Em 2013/14, possuía 56 turmas, um total de 1.398 alunos, aproximadamente 120 docentes, um diretor, quatro assistentes e mais de 100 funcionários. Contava com boa infraestrutura, salas de aula e equipamentos modernos e funcionais, auditório, biblioteca, laboratórios (Física, Química, Informática, Línguas) e planetário. O índice de reprovação foi de 13\% em 2009, 16\% em 2010 e 14\% em 2011.

A escola B também apresentou bons resultados nas avaliações nacionais. No Exame Nacional do Ensino Médio (Enem), a instituição pública foi a melhor de sua categoria em 2010. A nota obtida foi de 618,27 pontos, um aumento significativo em relação ao ano anterior, quando a pontuação foi de 589,89 . A nota média entre as escolas do país da mesma categoria foi 599 pontos.

Instituição muito procurada pela comunidade, no ano de 2013 possuía 35 turmas de Ensino Médio, 1.123 alunos, mais de 100 docentes, um diretor pedagógico e administrativo, dois assistentes e uma equipe pedagógica de oito profissionais. A escola contava com ótima infraestrutura (auditório, ginásio de esportes, biblioteca e laboratórios - Química, Física, Biologia, Informática e de Línguas). Todas as salas de aula contavam com lousa digital, datashow e computador. $\mathrm{O}$ índice de reprovação foi de $12 \%$ em $2009,9 \%$ em 2010 e $13 \%$ em 2011, e o nível socioeconômico médio da escola era médio e alto.

\section{Metodologia}

Este estudo, parte de uma pesquisa de pós-doutorado inserida em grupos de investigação localizados no Brasil e na Itália, procurou evidenciar e compreender, em duas realidades diferentes, os fatores escolares que explicam o desempenho acadêmico dos alunos sob a visão dos grupos envolvidos no processo de formação: família, alunos, professores e gestores. Tal compreensão foi construída a partir da perspectiva desses participantes e da vivência do pesquisador nas escolas. 
A seleção das escolas se prendeu ao fato de ambas serem reconhecidas em suas comunidades pela qualidade de ensino e, ao mesmo tempo, pelos seus resultados positivos em exames de larga escala em seus países. É necessário reconhecer as diferenças socioculturais dos países envolvidos e que, portanto, não é uma tarefa simples justificar o que de fato pode ser aprendido e compartilhado entre essas realidades escolares. No entanto, Phillips (2000) propôs algumas razões para favorecer a realização desse tipo de estudo: a descoberta de alternativas para a organização do sistema educacional ou das escolas, descrições para auxiliar em determinadas reformas, avaliando experiências similares em vários países e a possibilidade de fomentar a cooperação e o entendimento mútuo entre as nações, discutindo-se, política e culturalmente, as similaridades e diferenças e buscando explicações para elas.

$\mathrm{Na}$ presente pesquisa, utilizou-se a metodologia de estudo de caso com o propósito de compreender as realidades escolares (YIN, 2005), agrupando evidências por meio de um tipo de caso descritivo e exploratório (YIN, 1993) e possibilitando análises mais detalhadas. A exploração fornecerá elementos para a criação de um quadro explicativo sobre o desempenho dos alunos. Para a coleta de dados foram utilizados diferentes instrumentos pertencentes à pesquisa qualitativa, quantitativa, entrevistas e um questionário com questões objetivas e escalas do tipo Likert.

A opção pela utilização da pesquisa qualitativa ocorreu porque nesse tipo de estudo o problema é investigado dentro de seu contexto, por meio de coleta de dados, entre outras, descritiva. O objeto de estudo é o ponto de partida, analisando o ambiente investigado onde as pessoas atuam, conhecendo e compreendendo os significados (FLICK, 2004, p. 21-22).

$\mathrm{Na}$ pesquisa qualitativa, optou-se pelo uso de entrevistas. Foram entrevistados 10 pais, professores e alunos e quatro gestores da escola brasileira, e 12 participantes da escola italiana (três de cada grupo). Esse instrumento coletou informações sobre: 1) perfil dos participantes (gênero, idade, estado civil, formação, experiência profissional, estrutura familiar); 2) condições socioeconômicas (classe social, utilização de computadores, celulares, acesso à internet); 3) envolvimento com a educação do filho (participação da família na vida escolar); 4) capital cultural (escolaridade, domínio de línguas estrangeiras, viagens); 5) fatores que explicam o alto desempenho dos alunos.

As informações das entrevistas foram analisadas pela teoria fundamentada (CRESWELL, 2002), ideal para elaborar teorias subjetivas. Nessa abordagem qualitativa, os dados foram segmentados com a realização de uma investigação temática com codificação aberta. Posteriormente filtrados, utilizando códigos e descritores, identificando regularidades, similaridades e diferenças entre os depoimentos dos participantes. Surgiram então as categorias do estudo.

A estruturação desses dados serviu de base para a construção de um questionário que foi respondido na escola brasileira por 17 pais e alunos, 16 professores e quatro gestores, e na escola italiana por 15 familiares e professores, 14 alunos e três gestores. Ele continha informações sobre o perfil (gênero, idade, estado civil, formação, experiência profissional, condições socioeconômicas, estrutura familiar); formação; condições socioeconômicas (número de computadores, celulares, acesso à internet); envolvimento familiar (envolvimento da família na vida escolar do filho, com a escola e com os professores/gestores); capital cultural (escolaridade, domínio de línguas estrangeiras, viagens nacionais/internacionais); formação continuada (participação em cursos, conferências, pesquisas e produção de material); fatores que explicam o bom desempenho.

O Quadro 1 mostra os fatores que explicam o desempenho dos alunos identificados nas entrevistas brasileiras:

Quadro 1. Fatores que explicam o bom desempenho dos alunos identificados nas entrevistas iniciais.

\begin{tabular}{|l|l|c|l|}
\hline F01 & Os professores da escola, que fazem a diferença. & F12 & O tamanho da escola (a escola é pequena). \\
\hline F02 & O diretor e sua equipe, que fazem a diferença. & F13 & A disciplina (clima de ordem, o respeito às leis). \\
\hline F03 & $\begin{array}{l}\text { A infraestrutura, (biblioteca, computadores, internet, auditório, } \\
\text { laboratórios). }\end{array}$ & F14 & $\begin{array}{l}\text { O clima harmonioso. A escola é um lugar agradável para ensinar e } \\
\text { aprender. }\end{array}$ \\
\hline F04 & Os pais (envolvimento com estudos e apoio). & F15 & A relação com a comunidade, que participa da escola. \\
\hline F05 & Os alunos, que são dedicados e estudiosos. & F16 & O projeto pedagógico da escola, que é voltado para o aluno aprender. \\
\hline F06 & $\begin{array}{l}\text { A gestão da escola (que é organizada, planeja, apoia o trabalho } \\
\text { docente e controla o desempenho dos alunos). }\end{array}$ & F17 & A aprendizagem, que é o foco central da escola. \\
\hline F07 & $\begin{array}{l}\text { As lideranças (professores ou gestores que são líderes, organizam } \\
\text { projetos, motivam os alunos). }\end{array}$ & F18 & O trabalho em equipe dos professores e gestores. \\
\hline F08 & Os recursos financeiros de que a escola dispõe. & F19 & A estabilidade de emprego dos professores. \\
\hline F09 & $\begin{array}{l}\text { Os recursos didáticos disponíveis, tais como livros, livros didáticos e } \\
\text { paradidáticos, softwares educativos, }\end{array}$ & F20 & $\begin{array}{l}\text { As altas expectativas que os professores têm sobre o desempenho } \\
\text { dos alunos. }\end{array}$ \\
\hline F10 & A localização da escola, que fica num lugar privilegiado. & F21 & A não ocorrência de violência e de roubo. \\
\hline F11 & O currículo, que é planejado para o aluno aprender. & F22 & A avaliação frequente do aluno. \\
\hline
\end{tabular}


Quadro 2. Fatores que explicam o bom desempenho dos alunos identificados nas entrevistas iniciais.

\begin{tabular}{|l|l|l|l|}
\hline F01 & Os professores da escola, que fazem a diferença. & F12 & Os projetos pedagógicos executados na escola. \\
\hline F02 & O diretor e sua equipe, que fazem a diferença. & F13 & A disciplina (clima de ordem, respeito às leis). \\
\hline F03 & $\begin{array}{l}\text { A infraestrutura (biblioteca, computadores, internet, auditório, } \\
\text { laboratórios). }\end{array}$ & F14 & $\begin{array}{l}\text { O clima harmonioso. A escola é um lugar agradável para ensinar e } \\
\text { aprender. }\end{array}$ \\
\hline F04 & Os pais (envolvimento com estudos e apoio). & F15 & As leis de educação. \\
\hline F05 & Os alunos, que são dedicados e estudiosos. & F16 & O projeto pedagógico da escola, que é voltado para o aluno aprender. \\
\hline F06 & $\begin{array}{l}\text { A gestão da escola, que é organizada, planeja, apoia o trabalho } \\
\text { docente e controla o desempenho dos alunos. }\end{array}$ & F17 & A aprendizagem, que é o foco central da escola. \\
\hline F07 & O número menor de alunos na sala de aula. & F18 & O trabalho em equipe dos professores e gestores. \\
\hline F08 & Os recursos financeiros de que a escola dispõe. & $\mathbf{F 1 9}$ & A estabilidade de emprego dos professores. \\
\hline F09 & $\begin{array}{l}\text { Os recursos didáticos disponíveis, tais como livros, livros didáticos } \\
\text { e paradidáticos, softwares educativos. }\end{array}$ & F20 & $\begin{array}{l}\text { As altas expectativas que os professores têm sobre o desempenho } \\
\text { dos alunos. }\end{array}$ \\
\hline F10 & As aulas de reforço escolar. & F21 & A não ocorrência de violência e de roubo. \\
\hline F11 & O currículo, que é planejado para o aluno aprender. & F22 & A avaliação frequente do aluno. \\
\hline
\end{tabular}

Em relação aos fatores que explicam o desempenho dos alunos na realidade italiana, os dados das entrevistas brasileiras foram discutidos com pesquisadores italianos e entrevistas foram realizadas para a formulação do questionário final. Foram identificados 22 fatores. O Quadro 2 (acima) mostra os fatores identificados nas entrevistas.

No total, 104 participantes responderam ao questionário e 46 entrevistas foram realizadas nas duas realidades pesquisadas. Após as análises iniciais, outras reflexões e demandas foram encontradas. Tais questões foram investigadas por meio de novas entrevistas com os participantes. Na escola brasileira participaram dessas entrevistas finais oito familiares, oito professores, 10 alunos e três gestores. Foram investigadas as seguintes questões: para os pais ("Por que vocês consideraram os recursos didáticos disponíveis, tais como livros, livros didáticos e paradidáticos, softwares educativos, como um fator relevante para alavancar o desempenho do aluno na escola?"); para professores e alunos ("Por que a infraestrutura da escola para vocês não é um aspecto importante para a aprendizagem?").

$\mathrm{Na}$ escola italiana participaram dessas entrevistas finais seis familiares, oito professores, 10 alunos e quatro gestores. Para os gestores: "Os dados mostraram que vocês acreditam que os pais participam da formação de seus filhos, envolvendo-se com ela e com a escola. Poderiam falar um pouco sobre isso e como isso acontece? Vocês citaram que a dedicação dos alunos aos estudos é importante para a formação e para o desempenho nos exames. Por quê?". Para alunos e gestores: "Os recursos didáticos disponíveis, tais como livros, livros didáticos e paradidáticos, softwares educativos, foram reconhecidos como um fator importante pelos familiares e pelos professores. Alunos e os gestores não sinalizaram esses itens como fator relevante. Por quê?". Para professores: "Por que a estabilidade de emprego do corpo de professores e de funcionários foi reconhecida por vocês como um fator importante para o desempenho dos alunos?". Para os alunos: "Por que vocês não reconheceram o diretor e sua equipe e o trabalho em equipe como fatores relevantes para o desempenho dos alunos?".

\section{RESULTADOS E DISCUSSÃo}

Os resultados mostram inicialmente o perfil dos participantes da escola brasileira (Quadro 3).

Quadro 3. Perfil dos grupos da escola brasileira.

\begin{tabular}{|c|c|c|c|c|}
\hline & Familiares (\%) & Alunos (\%) & Professores (\%) & Gestores (\%) \\
\hline Sexo feminino & 95 & 60 & 30 & 65 \\
\hline Idade média & 47 & 16 & 44 & 51 \\
\hline Estado civil & 90 & - & 70 & 85 \\
\hline Formação superior & 55 & - & 100 & 100 \\
\hline Computador (pelo menos 1) & 100 & 100 & 100 & 100 \\
\hline Celular (ter ou não) & 100 & 100 & 100 & 100 \\
\hline Internet (acesso) & 100 & 100 & 100 & 100 \\
\hline Tempo de estudo (6 horas ) & - & 60 & - & - \\
\hline Frequência de estudo por semana ( 3 vezes) & - & 50 & - & - \\
\hline Experiencia profissional ( mais de 10 anos) & - & - & 75 & 75 \\
\hline Carga de trabalho semanal (40 horas) & - & - & 90 & 90 \\
\hline
\end{tabular}


Esse conjunto de pais, em geral, participava da vida estudantil de seus filhos, conversando com eles sobre a escola, acompanhando as tarefas de casa e participando de reuniões escolares. Eram pais leitores de jornais e livros. Os alunos se dedicavam aos estudos e também eram leitores de livros e jornais, dominavam outro idioma e costumavam estudar matérias da escola. Ambos os grupos utilizavam as tecnologias. O grupo de professores também utilizava as tecnologias, possuía algum tipo de assinatura em algum jornal local, tinha hábito regular de leitura de livros e participava de cursos de formação continuada. Os gestores realizavam formação continuada por meio de cursos e oficinas, explorando a produção de material didático como espaço de formação. Também realizavam viagens e eram leitores.

Quanto aos fatores explicativos do desempenho dos alunos, os dados foram sintetizados na Tabela 1 (abaixo), realizando uma aproximação entre as opiniões dos grupos.

Os dados mostraram que 16 itens foram citados com pontuações acima de 75\%; no entanto, alguns itens (fatores) foram citados somente por um ou dois grupos. Este é o caso dos recursos didáticos (FD09), que foi mencionado somente pelas famílias. Para compreender melhor esse aspecto, alguns pais que participaram do estudo foram entrevistados. Esses familiares revelaram que, estando fora da escola, observavam que seus filhos recebiam livros (Programa Nacional do Livro Didático - PNLEM), uniformes, materiais escolares, netbooks e tablets (Prefeitura Municipal) e que tais recursos eram usados pelos jovens. Esses familiares consideravam importantes esses recursos para auxiliar na aprendizagem do(a) filho(a). Portanto, quando se referiram aos recursos didáticos, estavam se reportando aos livros e aos dispositivos doados pelo governo federal e pelo município. Por outro lado, ressalta-se que para os outros grupos (professores, gestores e alunos) o nível de concordância desse item ficou entre $60 \%$ e $68 \%$, o que demonstra que esses participantes não desconsideravam totalmente a questão dos recursos didáticos. No entanto, a pontuação desses grupos ficou abaixo da linha de corte estabelecida nesta pesquisa (entre $75 \%$ e $100 \%$ ).

Tabela 1. Itens com pontuações acima de $75 \%$ e aqueles que obtiveram $100 \%$

\begin{tabular}{|c|c|c|c|c|c|c|c|c|c|}
\hline & & Pon & รัão & ma & $5 \%$ & Pon & ção & al - & \\
\hline & & $\mathbf{F}$ & $\mathbf{A}$ & $\mathbf{P}$ & G & $\mathbf{F}$ & $\mathbf{A}$ & $\mathbf{P}$ & G \\
\hline FD01 & Os professores da escola, que fazem a diferença. & - & - & - & - & $\mathrm{X}$ & $\mathrm{X}$ & $\mathrm{X}$ & $\mathrm{X}$ \\
\hline FD02 & O diretor e sua equipe, que fazem a diferença. & - & $\mathrm{X}$ & - & - & - & $\mathrm{X}$ & $\mathrm{X}$ & $\mathrm{X}$ \\
\hline FD03 & $\begin{array}{l}\text { A infraestrutura (biblioteca, computadores, internet, auditório, } \\
\text { laboratórios). }\end{array}$ & $\mathrm{X}$ & - & - & $\mathrm{X}$ & - & - & - & - \\
\hline FD05 & Os alunos, que são dedicados e estudiosos. & $\mathrm{X}$ & $\mathrm{X}$ & $\mathrm{X}$ & $\mathrm{X}$ & - & - & - & - \\
\hline FD06 & $\begin{array}{l}\text { A gestão da escola, que é organizada, planeja, apoia o trabalho } \\
\text { docente e controla o desempenho dos alunos. }\end{array}$ & - & $\mathrm{X}$ & $\mathrm{X}$ & - & $\mathrm{X}$ & - & - & $\mathrm{X}$ \\
\hline FD07 & $\begin{array}{l}\text { As lideranças (professores ou gestores que são líderes, organizam } \\
\text { projetos, motivam os alunos). }\end{array}$ & $\mathrm{X}$ & $\mathrm{X}$ & $\mathrm{X}$ & $\mathrm{X}$ & - & - & - & - \\
\hline FD09 & $\begin{array}{l}\text { Os recursos didáticos disponíveis, tais como livros, livros } \\
\text { didáticos e paradidáticos, softwares educativos. }\end{array}$ & $\mathrm{X}$ & - & - & - & - & - & - & - \\
\hline FD11 & O currículo, que é planejado para o aluno aprender. & $\mathrm{X}$ & - & $\mathrm{X}$ & $\mathrm{X}$ & - & $\mathrm{X}$ & - & - \\
\hline FD13 & A disciplina (clima de ordem, o respeito às leis e regulamentos). & $\mathrm{X}$ & $\mathrm{X}$ & $\mathrm{X}$ & $\mathrm{X}$ & - & - & - & - \\
\hline FD14 & $\begin{array}{l}\text { O clima harmonioso. A escola é um lugar agradável para ensinar e } \\
\text { aprender. }\end{array}$ & $\mathrm{X}$ & - & $\mathrm{X}$ & $\mathrm{X}$ & - & - & - & - \\
\hline FD16 & $\begin{array}{l}\text { O projeto pedagógico da escola, que é voltado para o aluno } \\
\text { aprender. }\end{array}$ & - & $\mathrm{X}$ & $\mathrm{X}$ & - & $\mathrm{X}$ & - & - & $\mathrm{X}$ \\
\hline FD17 & A aprendizagem, que é o foco central da escola. & - & - & $\mathrm{X}$ & - & $\mathrm{X}$ & $\mathrm{X}$ & & $\mathrm{X}$ \\
\hline FD18 & O trabalho em equipe dos professores e gestores. & $\mathrm{X}$ & $\mathrm{X}$ & $\mathrm{X}$ & - & - & - & - & $\mathrm{X}$ \\
\hline FD19 & $\begin{array}{l}\text { A estabilidade de emprego do corpo de professores e de } \\
\text { funcionários, }\end{array}$ & - & $\mathrm{X}$ & $\mathrm{X}$ & $\mathrm{X}$ & - & - & - & - \\
\hline FD20 & $\begin{array}{l}\text { As altas expectativas que os professores têm sobre o desempenho } \\
\text { dos alunos. }\end{array}$ & - & - & $\mathrm{X}$ & $\mathrm{X}$ & $\mathrm{X}$ & - & - & - \\
\hline FD21 & A não ocorrência de violência e de roubo. & $\mathrm{X}$ & $\mathrm{X}$ & - & - & - & - & - & - \\
\hline FD22 & A avaliação frequente do aluno. & $\mathrm{X}$ & $\mathrm{X}$ & - & - & - & - & $X$ & $X$ \\
\hline
\end{tabular}

F - família; A - alunos; P - professores; G - gestores. 
Tabela 2. Itens com concordância de todos os quatro grupos.

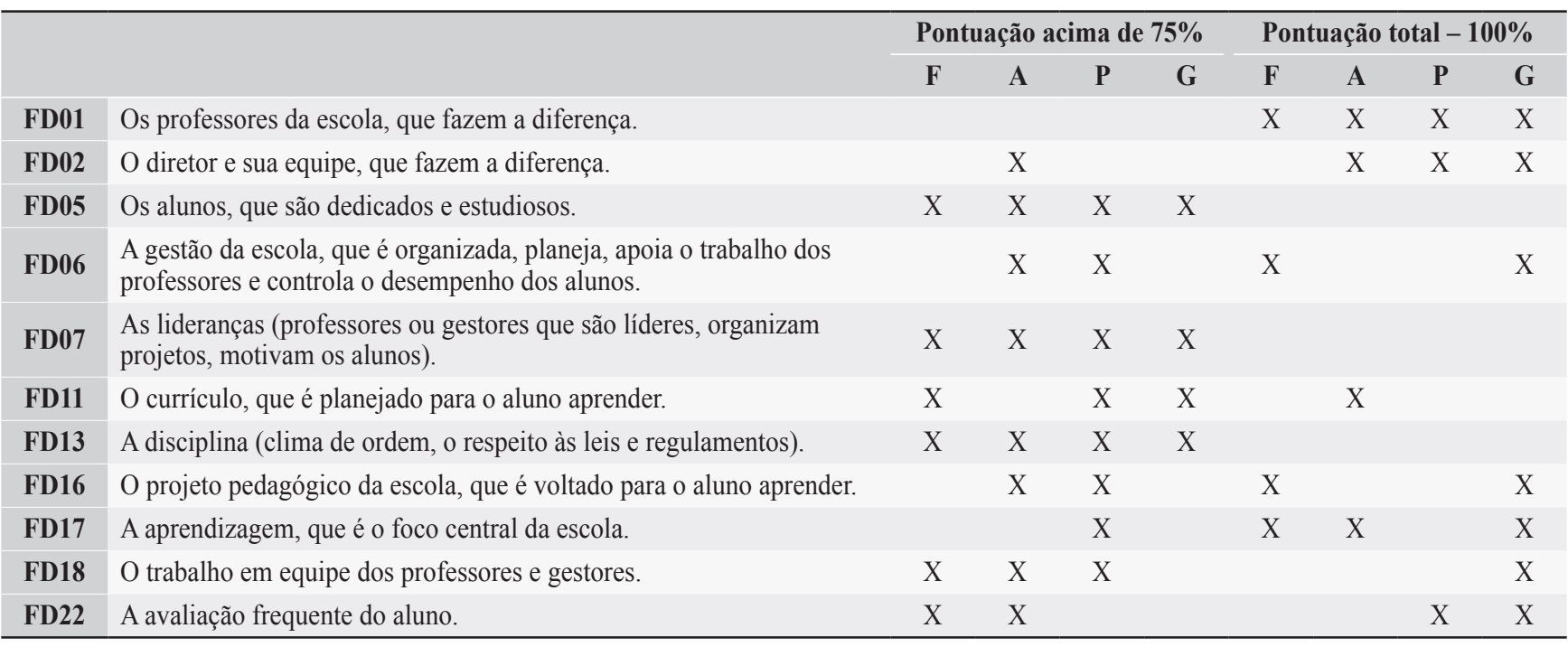

Outra questão relevante relaciona-se à infraestrutura, que foi citada somente por pais e gestores. Observou-se que aqueles que estavam mais distantes da sala de aula foram os que mais acreditaram na infraestrutura como um fator que poderia promover a aprendizagem do aluno. Entrevistas mostraram que esses participantes não desconsideravam a infraestrutura da escola. Mas, como eles enfrentavam mais diretamente e cotidianamente problemas, por exemplo, com a internet que às vezes não funcionava, com a falta de alguns elementos para experiências nos laboratórios e algumas vezes com a falta de som no auditório, tais situações os impulsionaram a não indicar a infraestrutura com elemento-chave. Mesmo assim, eles reconheciam a importância da infraestrutura na escola para a aprendizagem e para o desempenho dos alunos, o que confirmam as pesquisas brasileiras, mostrando que a infraestrutura impacta a aprendizagem dos estudantes (CASTRO; FLETCHER, 1986; FRANCO, ALBERNAZ e ORTIGÃO, 2007; SOARES, MAMBRINI, PEREIRA e ALVES, 2001; LEE, FRANCO e ALBERNAZ, 2004; ESPÓSITO, DAVIS e NUNES, 2000). No Brasil, a infraestrutura das escolas faz diferença no desempenho dos alunos.

A Tabela 2 (acima) mostra os fatores, com a concordância de todos os grupos.

Independentemente do perfil (gênero, idade), formação, acesso às tecnologias, capital cultural e grau de participação na escola, todos os grupos concordaram como sendo fatores importantes para o desempenho dos alunos: o fator diretor e sua equipe, suas formas de gestão, incluindo a organização da escola e a disciplina escolar; o esforço dos alunos, realizando os deveres de casa e fazendo leituras, entre outros. No entanto, o principal fator citado para o sucesso do aluno foi o professor, o que vai ao encontro dos estudos de Klein e Fontanive (2010) e Scartezini e Viana (2012), que afirmaram que o fator mais determinante do alto desempenho dos alunos é o professor. Não há, portanto, uma categoria que explique isoladamente o bom desempenho dos alunos na opinião dos participantes.

A Tabela 3 mostra a opinião daqueles que estão mais próximos do processo de ensino e aprendizagem: professores e gestores.

Tabela 3. Itens com concordância entre professores e gestores

\begin{tabular}{|c|c|c|c|}
\hline & & $\mathbf{P}$ & G \\
\hline FD01 & Os professores da escola, que fazem a diferença. & $\mathrm{X}$ & $\mathrm{X}$ \\
\hline FD02 & O diretor e sua equipe, que fazem a diferença. & $\mathrm{X}$ & $\mathrm{X}$ \\
\hline FD03 & $\begin{array}{l}\text { A infraestrutura (biblioteca, computadores, } \\
\text { internet, auditório, laboratórios). }\end{array}$ & - & $\mathrm{X}$ \\
\hline FD05 & Os alunos, que são dedicados e estudiosos. & $\mathrm{X}$ & $\mathrm{X}$ \\
\hline FD06 & $\begin{array}{l}\text { A gestão da escola, que é organizada, planeja, } \\
\text { apoia o trabalho docente e controla o desempenho } \\
\text { dos alunos. }\end{array}$ & $\mathrm{X}$ & $\mathrm{X}$ \\
\hline FD07 & $\begin{array}{l}\text { As lideranças (professores ou gestores que são } \\
\text { líderes, organizam projetos, motivam os alunos). }\end{array}$ & $\mathrm{X}$ & $\mathrm{X}$ \\
\hline FD11 & O currículo, que é planejado para o aluno aprender. & $\mathrm{X}$ & $\mathrm{X}$ \\
\hline FD13 & $\begin{array}{l}\text { A disciplina (clima de ordem, o respeito às leis e } \\
\text { regulamentos). }\end{array}$ & $\mathrm{X}$ & $\mathrm{X}$ \\
\hline FD14 & $\begin{array}{l}\text { O clima harmonioso. A escola é um lugar } \\
\text { agradável para ensinar e aprender. }\end{array}$ & $\mathrm{X}$ & $\mathrm{X}$ \\
\hline FD16 & $\begin{array}{l}\text { O projeto pedagógico da escola, que é voltado } \\
\text { para o aluno aprender. }\end{array}$ & $\mathrm{X}$ & $\mathrm{X}$ \\
\hline FD17 & A aprendizagem, que é o foco central da escola. & $\mathrm{X}$ & $\mathrm{X}$ \\
\hline FD18 & O trabalho em equipe dos professores e gestores. & $\mathrm{X}$ & $\mathrm{X}$ \\
\hline FD19 & $\begin{array}{l}\text { A estabilidade de emprego do corpo de } \\
\text { professores e de funcionários, }\end{array}$ & $\mathrm{X}$ & $\mathrm{X}$ \\
\hline FD20 & $\begin{array}{l}\text { As altas expectativas que os professores têm } \\
\text { sobre o desempenho dos alunos. }\end{array}$ & $\mathrm{X}$ & $\mathrm{X}$ \\
\hline FD22 & A avaliação frequente do aluno. & $\mathrm{X}$ & $\mathrm{X}$ \\
\hline
\end{tabular}


Analisando os dados dos professores e dos gestores, aqueles que estão mais próximos do processo de ensino e aprendizagem, observa-se que 15 fatores foram indicados como promotores do bom desempenho dos alunos. Esses fatores apresentaram opiniões bastante similares. A única discordância foi em relação à infraestrutura. Tal situação parece indicar um discurso mais sintonizado em relação aos fatores que impactam o desempenho dos alunos. Uma das explicações para esse fato baseia-se na ideia de que muitas decisões, sobretudo as de cunho pedagógico, são tomadas de forma coletiva nessa escola. Ou seja, gestores e professores trabalham juntos em muitas atividades e, por tal motivo, constroem juntos significados. A construção coletiva dos significados e sentidos na escola apresenta-se como um aspecto relevante, pois, como advogam Fullan e Hargreaves (2000) e Thurler (2001), sem ela muitas mudanças estão fadadas ao fracasso.

\section{A ESCOLA ITALIANA}

Os resultados mostram inicialmente o perfil dos participantes da escola italiana (Quadro 4, abaixo).

Esse conjunto de pais, em geral, conversava com seus filhos sobre a escola, sobre a aprendizagem e sobre os professores. Participava das reuniões de pais e mestres e visitava as escolas. Eram familiares leitores e que dominavam outro idioma. Os alunos se dedicavam aos estudos, costumavam estudar as matérias da escola e fazer as lições solicitadas, dominavam outro idioma e dialogavam com os pais. Ambos os grupos utilizavam as tecnologias. Seus professores também usavam as tecnologias, eram leitores, viajavam constantemente, participavam de formação por meio da realização de pesquisas acadêmicas, participação em cursos, oficinas e congressos. Os gestores, por fim, eram leitores, dominavam outro idioma, realizavam cursos, participavam de conferências, de redes de conhecimento e visitavam outras escolas.

A Tabela 4 (adiante) mostra os itens em que a maioria dos grupos concordou serem os fatores explicativos do bom desempenho dos estudantes.

Dos 17 itens citados com pontuações acima de $65 \%$, alguns foram apontados somente por um ou dois grupos. Os itens FD04 (envolvimento dos pais) e FD05 (dedicação dos alunos) foram mencionados somente pelos gestores. Entrevistas foram utilizadas para entender melhor esses dados.

Em relação à família, os gestores acreditavam que ela contribuía com a aprendizagem de seus filhos, incentivando-os para o estudo, participando das atividades e das reuniões da escola e punindo-os quando necessário. Quanto aos alunos, eles mencionaram o esforço realizado como determinante de seus desempenhos, já que a escola era muito exigente em relação às atividades e aos estudos cotidianos. Por outro lado, é interessante observar que os professores não reconheceram as famílias como parceiras no processo de ensino e aprendizagem.

O item FD09 (recursos didáticos disponíveis) foi reconhecido como um fator importante pelos familiares e pelos professores. Entrevistas mostraram que para os estudantes, em geral, os recursos existem e estão presentes na escola, mas eles percebem a ausência de tecnologias e computadores nas aulas cotidianas. Portanto, para esses estudantes, recursos didáticos estavam mais atrelados às tecnologias. Os gestores também reconheceram que esses recursos estavam presentes na escola, no entanto afirmaram que há a necessidade de esses serem mais diferenciados para, por exemplo, os alunos de inclusão. Como afirmou um participante: "Precisamos de mais recursos para lidar com os alunos que têm necessidades especiais" (GESTOR 01).

Quadro 4. Perfil dos grupos da escola italiana.

\begin{tabular}{|c|c|c|c|c|}
\hline & Familiares (\%) & Alunos (\%) & Professores (\%) & Gestores (\%) \\
\hline Sexo feminino & 60 & 60 & 55 & - \\
\hline Idade média & 48 & 16 & 50 & 53 \\
\hline Estado civil & 90 & - & 80 & 75 \\
\hline Formação superior & 55 & - & 100 & 100 \\
\hline Computador (pelo menos 1) & 100 & 100 & 100 & 100 \\
\hline Celular (ter ou não) & 100 & 100 & 100 & 100 \\
\hline Internet (acesso) & 100 & 100 & 100 & 100 \\
\hline Tempo de estudo (15 horas ) & - & 60 & - & - \\
\hline Frequência de estudo por semana ( 3 vezes) & - & 60 & - & - \\
\hline Experiencia profissional (mais de 10 anos) & - & - & 80 & 50 \\
\hline Carga de trabalho semanal (40 horas) & - & - & 60 & 100 \\
\hline
\end{tabular}


Tabela 4. Itens com pontuações acima de $65 \%$ e aqueles que obtiveram $100 \%$.

\begin{tabular}{|c|c|c|c|c|c|c|c|c|c|}
\hline & \multicolumn{4}{|c|}{ Pontuação acima de $65 \%$} & \multicolumn{4}{|c|}{ Pontuação total - $100 \%$} \\
\hline & & $\mathbf{F}$ & $\mathbf{A}$ & $\mathbf{P}$ & G & $\mathbf{F}$ & A & $\mathbf{P}$ & G \\
\hline FD01 & Os professores da escola, que fazem a diferença. & - & - & - & - & $\mathrm{X}$ & $\mathrm{x}$ & $\mathrm{X}$ & $\mathrm{X}$ \\
\hline FD02 & O diretor e sua equipe, que fazem a diferença. & $\mathrm{X}$ & - & - & - & - & - & $\mathrm{X}$ & $\mathrm{X}$ \\
\hline FD03 & $\begin{array}{l}\text { A infraestrutura (biblioteca, computadores, internet, auditório, } \\
\text { laboratórios). }\end{array}$ & $\mathrm{X}$ & $\mathrm{X}$ & $\mathrm{X}$ & $\mathrm{X}$ & - & - & - & - \\
\hline FD04 & Os pais (envolvimento com os estudos e apoio). & - & - & - & - & - & - & - & $\mathrm{X}$ \\
\hline FD05 & Os alunos, que são dedicados e estudiosos. & - & - & - & - & - & - & - & $\mathrm{X}$ \\
\hline FD06 & $\begin{array}{l}\text { A gestão da escola, que é organizada, planeja, apoia o trabalho dos } \\
\text { professores e controla o desempenho dos alunos. }\end{array}$ & $\mathrm{X}$ & $\mathrm{X}$ & $\mathrm{X}$ & - & - & - & - & $\mathrm{X}$ \\
\hline FD08 & Os recursos financeiros de que a escola dispõe. & $\mathrm{X}$ & - & $\mathrm{X}$ & - & - & - & - & - \\
\hline FD09 & $\begin{array}{l}\text { Os recursos didáticos disponíveis, tais como livros, livros didáticos e } \\
\text { paradidáticos, softwares educativos, }\end{array}$ & $\mathrm{X}$ & - & $\mathrm{X}$ & - & - & - & - & - \\
\hline FD11 & O currículo, que é planejado para o aluno aprender. & $\mathrm{X}$ & $\mathrm{X}$ & $\mathrm{X}$ & $\mathrm{X}$ & - & - & - & - \\
\hline FD13 & A disciplina (clima de ordem, o respeito às leis e regulamentos). & $\mathrm{X}$ & $\mathrm{X}$ & $\mathrm{X}$ & $\mathrm{X}$ & - & - & - & - \\
\hline FD14 & $\begin{array}{l}\text { O clima harmonioso. A escola é um lugar agradável para ensinar e } \\
\text { aprender. }\end{array}$ & $\mathrm{X}$ & $\mathrm{X}$ & $\mathrm{X}$ & - & - & - & - & $\mathrm{X}$ \\
\hline FD16 & O projeto pedagógico da escola, que é voltado para o aluno aprender. & - & - & $\mathrm{X}$ & $\mathrm{X}$ & $\mathrm{X}$ & $\mathrm{x}$ & - & - \\
\hline FD17 & A aprendizagem, que é o foco central da escola. & $\mathrm{X}$ & $\mathrm{X}$ & - & - & - & - & $\mathrm{X}$ & $\mathrm{X}$ \\
\hline FD18 & $\mathrm{O}$ trabalho em equipe dos professores e gestores. & $\mathrm{X}$ & - & $\mathrm{X}$ & - & - & - & - & $\mathrm{X}$ \\
\hline FD19 & A estabilidade de emprego do corpo de professores e de funcionários. & - & - & $\mathrm{X}$ & - & - & - & - & - \\
\hline FD21 & A não ocorrência de violência e de roubo. & $\mathrm{X}$ & - & $\mathrm{X}$ & - & - & - & - & - \\
\hline FD22 & A avaliação frequente do aluno. & $\mathrm{X}$ & $\mathrm{X}$ & - & - & - & - & $\mathrm{X}$ & $\mathrm{X}$ \\
\hline
\end{tabular}

F - família; A - alunos; P - professores; $\mathbf{G}$ - gestores.

Da mesma forma, o item FD19 (a estabilidade de emprego do corpo de professores e de funcionários) foi reconhecido pelos professores e pelos familiares como um fator importante para o desempenho dos alunos. Os professores entrevistados realizaram afirmações de que tal fato proporciona mais "tranquilidade" para trabalhar, aliviando o docente de preocupações relacionadas ao desemprego. De fato, dados de 2013, do Istituto Nazionale di Statistica (Insat: http://www.istat.it/it/), mostraram que o desemprego nesse período chegava a $40 \%$ entre os jovens de 15 a 24 anos.

A Tabela 5 mostra os itens em que a maioria dos grupos concordou serem os fatores explicativos do bom desempenho dos estudantes.

Tabela 5. Maioria dos itens com pontuações acima de $65 \%$ e aqueles que obtiveram $100 \%$.

\begin{tabular}{|c|c|c|c|c|c|c|c|c|c|}
\hline & \multicolumn{4}{|c|}{ Pontuação acima de $65 \%$} & \multicolumn{4}{|c|}{ Pontuação total - $100 \%$} \\
\hline & & $\mathbf{F}$ & $\mathbf{A}$ & $\mathbf{P}$ & G & $\mathbf{F}$ & $\mathbf{A}$ & $\mathbf{P}$ & G \\
\hline FD01 & Os professores da escola, que fazem a diferença. & - & - & - & - & $\mathrm{X}$ & $\mathrm{X}$ & $\mathrm{X}$ & $\mathrm{X}$ \\
\hline FD02 & O diretor e sua equipe, que fazem a diferença. & $\mathrm{X}$ & - & - & - & - & - & $\mathrm{X}$ & $\mathrm{X}$ \\
\hline FD03 & $\begin{array}{l}\text { A infraestrutura (biblioteca, computadores, internet, auditório, } \\
\text { laboratórios). }\end{array}$ & $\mathrm{X}$ & $\mathrm{X}$ & $\mathrm{X}$ & $\mathrm{X}$ & - & - & - & - \\
\hline FD06 & $\begin{array}{l}\text { A gestão da escola, que é organizada, planeja, apoia o trabalho dos } \\
\text { professores e controla o desempenho dos alunos. }\end{array}$ & $\mathrm{X}$ & $\mathrm{X}$ & $\mathrm{X}$ & - & - & - & - & $\mathrm{X}$ \\
\hline FD11 & O currículo, que é planejado para o aluno aprender. & $\mathrm{X}$ & $\mathrm{X}$ & $\mathrm{X}$ & $\mathrm{X}$ & - & - & - & - \\
\hline FD13 & A disciplina (clima de ordem, o respeito às leis e regulamentos). & $\mathrm{X}$ & $\mathrm{X}$ & $\mathrm{X}$ & $\mathrm{X}$ & - & - & - & - \\
\hline FD14 & $\begin{array}{l}\text { O clima harmonioso. A escola é um lugar agradável para ensinar e } \\
\text { aprender. }\end{array}$ & $\mathrm{X}$ & $\mathrm{X}$ & $\mathrm{X}$ & - & - & - & - & $\mathrm{X}$ \\
\hline FD16 & O projeto pedagógico da escola, que é voltado para o aluno aprender. & - & - & $\mathrm{X}$ & $\mathrm{X}$ & $\mathrm{X}$ & $\mathrm{X}$ & - & - \\
\hline FD17 & A aprendizagem, que é o foco central da escola. & $\mathrm{X}$ & $\mathrm{X}$ & - & - & - & - & $\mathrm{X}$ & $\mathrm{X}$ \\
\hline FD18 & O trabalho em equipe dos professores e gestores. & $\mathrm{X}$ & - & $\mathrm{X}$ & - & - & - & - & $\mathrm{X}$ \\
\hline FD22 & A avaliação frequente do aluno. & $\mathrm{X}$ & - & - & - & - & - & $\mathrm{X}$ & X \\
\hline
\end{tabular}


Onze itens foram ranqueados como aqueles que tiveram maior efeito no desempenho dos alunos. Alguns deles com 100\% de concordância. Os itens FD02 e FD18, relacionados ao diretor e sua equipe e ao trabalho em equipe, não foram reconhecidos pelos alunos como fatores relevantes para o desempenho. Entrevistas mostraram que o pouco contato dos alunos com esses profissionais foi a principal justificativa para a não sinalização de tais fatores. Ou seja, os jovens não tinham um contato muito direto com diretores e assistentes. Como descrito por um estudante: "Temos pouco contato com os diretores da escola, pouco os vemos no dia a dia, fica difícil de dizer se eles trabalham juntos ou não" (ALUNO, 06).

Independentemente do gênero, idade, estado civil, formação, acesso às tecnologias, capital cultural e grau de participação na escola, oito itens foram reconhecidos por todos os grupos como sendo fatores explicativos do bom desempenho dos alunos: os professores, a infraestrutura, a gestão da escola, o currículo, a disciplina, o clima harmonioso, o projeto pedagógico e a aprendizagem com o foco da escola.

A Tabela 6 traz os itens com o olhar daqueles que estão mais próximos do processo de ensino e aprendizagem: professores e gestores.

Tabela 6. Itens com concordância entre professores e gestores.

\begin{tabular}{|c|c|c|c|}
\hline & & $\mathbf{P}$ & G \\
\hline FD01 & Os professores da escola, que fazem a diferença. & $\mathrm{X}$ & $\mathrm{X}$ \\
\hline FD02 & O diretor e sua equipe, que fazem a diferença. & $\mathrm{X}$ & $\mathrm{X}$ \\
\hline FD03 & $\begin{array}{l}\text { A infraestrutura (biblioteca, computadores, } \\
\text { internet, auditório, laboratórios). }\end{array}$ & $\mathrm{X}$ & $\mathrm{X}$ \\
\hline FD04 & Os pais (envolvimento com os estudos e apoio). & - & $\mathrm{X}$ \\
\hline FD05 & Os alunos, que são dedicados e estudiosos. & - & $\mathrm{X}$ \\
\hline FD06 & $\begin{array}{l}\text { A gestão da escola, que é organizada, planeja, } \\
\text { apoia o trabalho dos professores e controla o } \\
\text { desempenho dos alunos. }\end{array}$ & $\mathrm{X}$ & $\mathrm{X}$ \\
\hline FD08 & Os recursos financeiros de que a escola dispõe. & $\mathrm{X}$ & - \\
\hline FD09 & $\begin{array}{l}\text { Os recursos didáticos disponíveis, tais como } \\
\text { livros, livros didáticos e paradidáticos, } \\
\text { softwares educativos, }\end{array}$ & $\mathrm{X}$ & - \\
\hline FD11 & $\begin{array}{l}\text { O currículo, que é planejado para o aluno } \\
\text { aprender. }\end{array}$ & $\mathrm{X}$ & $\mathrm{X}$ \\
\hline FD13 & $\begin{array}{l}\text { A disciplina (clima de ordem, o respeito às leis } \\
\text { e regulamentos). }\end{array}$ & $\mathrm{X}$ & $\mathrm{X}$ \\
\hline FD14 & $\begin{array}{l}\text { O clima harmonioso. A escola é um lugar } \\
\text { agradável para ensinar e aprender. }\end{array}$ & $\mathrm{X}$ & $\mathrm{X}$ \\
\hline FD16 & $\begin{array}{l}\text { O projeto pedagógico da escola, que é voltado } \\
\text { para o aluno aprender. }\end{array}$ & $\mathrm{X}$ & $\mathrm{X}$ \\
\hline FD17 & A aprendizagem, que é o foco central da escola. & $\mathrm{X}$ & $\mathrm{X}$ \\
\hline FD18 & O trabalho em equipe dos professores e gestores. & $\mathrm{X}$ & $\mathrm{X}$ \\
\hline FD19 & $\begin{array}{l}\text { A estabilidade de emprego do corpo de } \\
\text { professores e de funcionários. }\end{array}$ & $\mathrm{X}$ & - \\
\hline FD21 & A não ocorrência de violência e de roubo. & $\mathrm{X}$ & - \\
\hline FD22 & A avaliação frequente do aluno. & $\mathrm{X}$ & $\mathrm{X}$ \\
\hline
\end{tabular}

Professores e gestores possuem algumas opiniões diferentes em relação aos fatores que determinam o desempenho dos alunos. Mas concordaram que os fatores relacionados aos professores, ao diretor e a sua equipe, à infraestrutura da escola, à gestão, ao currículo, à disciplina escolar, ao clima escolar, ao projeto pedagógico, à aprendizagem, que é o foco da escola, e ao trabalho em equipe são importantes. No entanto, há divergências. Professores acreditavam que os recursos financeiros e didáticos, a estabilidade de emprego e a não ocorrência de violência eram fatores que contribuíam para o sucesso dos alunos. Por outro lado, os gestores acreditavam mais nos pais e nos alunos.

\section{CONSIDERAÇÕES FINAIS}

Este estudo evidenciou os fatores escolares que explicam o bom desempenho acadêmico dos alunos a partir da perspectiva dos pais, alunos, professores e gestores. Trata-se de uma demanda específica de participantes de culturas diferentes, que não permite comparação. No entanto, a descrição desses fatores auxilia a refletir sobre a organização da escola (PHILLIPS, 2000) e sobre os fatores que nela atuam.

Os fatores identificados, em cada realidade, fornecem informações relevantes para os gestores atuarem na melhoria de suas escolas. Ressalta-se que vários deles também já foram encontrados em outros estudos nacionais e internacionais (WILLMS, 1992; LEE, BRYK E SMITH, 1993; SAMMONS, HILLMAN E MORTIMORE, 1995; MEURET, 2000; SCHEERENS e BOSKER, 1997; SCHEERENS, 2000) e outros nacionais (CASTRO e FLETCHER, 1986; SOARES; MAMBRINI; PEREIRA; ALVES, 2001; LEE; FRANCO; ALBERNAZ, 2004; FRANCO, ALBERNAZ e ORTIGÃO, 2007; SOARES e ALVES, 2003; MACHADO SOARES, 2004; KLEIN e FONTANIVE, 2010; SCARTEZINI e VIANA, 2012), valorizando e reforçando a ideia de que é necessário dar voz e dialogar com aqueles que estão dentro e fora do contexto escolar, além de realizar outros tipos de pesquisa.

Na realidade italiana, 17 fatores foram citados por um ou mais grupos, 17 pelos professores e gestores e 11 por todos os grupos. O principal fator citado foi o professor. $\mathrm{Na}$ realidade brasileira, 16 fatores foram citados por um ou mais grupos, 15 pelos professores e gestores e 12 por todos os grupos como explicativos do desempenho dos jovens: o diretor e sua equipe, os alunos, a gestão da escola, os líderes da escola, o currículo, a disciplina escolar, o projeto político pedagógico, a aprendizagem como foco da escola, o trabalho em equipe e a avaliação frequente do aluno. $\mathrm{O}$ principal fator também foi o professor, que é determinante no rendimento do aluno. No entanto, ainda não se conhece em detalhes os 
atributos dos bons professores (GOMEZ, 2005) e nem as particularidades de suas práticas pedagógicas que influenciam na aprendizagem dos alunos.

Embora não se pretenda realizar comparações, alguns fatores foram comuns às duas realidades: professor, gestão escolar, currículo planejado para o aluno aprender, disciplina e clima de ordem, projeto pedagógico, aprendizagem como foco central da escola e avaliação do aluno frequentemente. Independentemente do perfil do participante, da cultura local, sete fatores emergiram como determinantes do bom desempenho dos alunos. Isso traz pistas importantes para os gestores escolares e para as autoridades brasileiras e italianas, pois trata-se das percepções daqueles que estão envolvidos no processo de ensino e aprendizagem.

Depreende-se dos dados que em ambas as realidades não há um fator isolado que explique o bom desempenho dos alunos. Existe, pode-se afirmar, um campo magnético formado por múltiplos fatores que sustentam e apoiam a aprendizagem e o bom desempenho dos estudantes. Como Rutter et al. (1979) mostraram, há na escola uma variedade de mecanismos, agindo de forma combinada, que é mais poderoso do que qualquer fator individual agindo isoladamente. Esses pesquisadores sugeriram que há um tipo de "ethos" global na escola. Também Barbosa e Fernandes (2001) afirmaram que múltiplos fatores atuam, concomitantemente, em vários níveis da inserção social para determinar o bom desempenho dos alunos e que o resultado advém dessa complexa interação. No entanto, esses fatores não atuam e influenciam os alunos da mesma forma, eles têm peculiaridades próprias. Além disso, possivelmente, apresentam intensidades diversas ao longo do ano.

Conhecer esses fatores que atuam conjuntamente, a partir da perspectiva daqueles que estão envolvidos no processo de formação dos alunos, permite e sustenta o avanço para uma investigação mais detalhada e profunda de como eles funcionam na realidade escolar e na sala de aula, influenciando o desempenho dos estudantes. Paralelamente, permite também investigar sobre o comportamento desses fatores e suas intensidades ao longo do ano. O conhecimento de tal situação possibilitaria, para cada gestor escolar, informações, ou mesmo um modelo, para melhorar sua escola e o desempenho dos alunos.

\section{Agradecimentos}

Expressamos agradecimentos ao senhor Giuseppe Pellegrini, Università Degli Studi di Padova, Observa Science in Society, Núcleo de pesquisa em Educação, Divulgação e Epistemologia da Evolução Biológica (EDEVO-Darwin) e a Universidade de São Caetano do Sul (Observatório de Educação do Grande ABC Paulista).

\section{REFERÊNCIAS}

ALBERNAZ, A; FERREIRA, F. H. G.; FRANCO, C. Qualidade e equidade na educação fundamental brasileira. Texto para Discussão no 455. Rio de Janeiro: PUC-Rio, 2002.

BARBOSA, M. E. F.; FERNANDES, C. A escola brasileira faz diferença? Uma investigação dos efeitos da escola na proficiência em matemática dos alunos da 4a série. In: FRANCO, Creso (Org.). Avaliação, ciclos e promoção na educação. Porto Alegre: Artmed, 2001, p. 121-153.

BROOKE, N. SOARES, J. F. (Org.). Pesquisa em eficácia escolar: origens e trajetórias. Belo Horizonte: Editora da UFMG, 2008.

CASTRO, C. M.; FLETCHER, P. A escola que os brasileiros frequentaram em 1985. Rio de Janeiro: Ipea, Iplan, 1986.

CASTRO, C. M.; SANGUINETTY J. A.; MARQUES, E. A.; LACERDA, E. R.; FRANCO, M. A. C.; SILVA, M. A. Determinantes de la educación en América Latina: acceso, desempeño y equidad. ECIEL. Rio de Janeiro: Fundação Getúlio Vargas (1984).

CASASSUS, J. A escola e a desigualdade. Brasília, DF: Plano, 2002.

CÉSAR, C.; SOARES, J. Desigualdades acadêmicas induzidas pelo contexto escolar. Revista Brasileira de Estudos de População, v. 18, n. 1/2, p. 97-110, 2001.

COLEMAN, J. S. Equality of educational opportunity. Washington, DC: US Government Print, Office, 1966.

CRESWELL, J. Educational research: planning, conducting, and evaluating quantitative and qualitative research. New Jersey: Merrill Prentice Hall, 2005.

CRESAS. Le handicap socioculturel en question. Paris: ESF, 1978.

CRAHAY, M. Poderá a escola ser justa e eficaz? Da igualdade das oportunidades à igualdade dos conhecimentos. Tradução de Vasco Farinha. Lisboa: Instituto Piaget, 2002.

CRAHAY, M.; BAYE, A. Existem escolas justas e eficazes? Cad. Pesq., São Paulo, v. 43, n. 150, 2013. Disponível em:<http://www. scielo.br/scielo.php?script=sci_arttext\&pid=S0100-15742013 000300007\&lng=pt\&nrm=iso $>$. Acesso em: 27 jun. 2014.

DOUGLAS, J. W. B.; ROSS, J. M.; SIMPSON, H. R. All our future. London: P. Davies, 1968.

ESPÓSITO, Y. L.; DAVIS, C.; NUNES, M. M. R. Sistema de Avaliação do Rendimento Escolar - O modelo adotado pelo estado de São Paulo. Revista Brasileira de Educação, n. 13, p. $25-53,2000$.

FELICIO, F.; FERNANDES, R. O efeito da qualidade da escola sobre o desempenho escolar: uma avaliação do ensino fundamental no estado de São Paulo. Anais do XXXIII Encontro Nacional de Economia. Natal-RN, 2005.

FERNANDES, N. S.; SOARES, T. M.; PENA, A. C.; CUNHA, I. C. O conhecimento do professor em avaliação educacional e a proficiência do aluno. Est. Aval. Educ., São Paulo, v. 21, n. 47, p. 569-590, 2010.

FERRÃO, M. E.; BELTRÃO, K.; SANTOS, D. Políticas de não-repetência e qualidade da educação: evidências obtidas a partir da modelagem dos dados da 4⿳亠丷a série do SAEB-99. Estudos em Avaliação Educacional, n. 26, 2002. 
FERRÃO, M. E.; BELTRÃO, K. I.; FERNANDES, C. Aprendendo sobre Escola Eficaz - evidências do SAEB-99. INEP/MEC, 2002.

FLETCHER, P. À procura do ensino eficaz. Relatório de pesquisa, PNUD/MEC/SAEB, 1997.

FLICK, U. Uma introdução à pesquisa qualitativa. 3. ed. Porto Alegre: Bookman, 2009.

FRANCO, C.; BONAMINO, A. A pesquisa sobre características de escolas eficazes no Brasil: breve revisão dos principais achados e alguns problemas em aberto. Revista Educação Online, Rio de Janeiro, n. 1, 2005. Disponível em: <http://www. maxwell.lambda.ele.puc-rio.br>. Acesso em: 10 fev. 2013.

FRANCO, C.; SZTAJN, P.; ORTIGÃO, M. I. Mathematics teachers, reform, and equity: results from the Brazilian National Assessment. Journal for Research in Mathematics Education, Reston, Virginia, v. 38, n. 4, 393-419, 2007.

FULLAN, M.; HARGREAVES, A. A escola como organização aprendente: buscando uma qualidade para a Educação. Porto Alegre: Artmed, 2000.

GOMES, C. A. A escola de qualidade para todos: abrindo as camadas da cebola. Ensaio: Avaliação de Políticas Públicas Educacionais, n. 13, p. 281-306, jul.-set. 2005.

KLEIN, R.; FONTANIVE, N. S. Gestão de resultados e de aprendizagem. Apresentado no XIV Encontro Nacional de Diretores (Fundação Bradesco). Gestão escolar: as articulações do diretor, São Paulo, 2010.

Instituto Nacional de Pesquisas (Inep). Censo da Educação Básica, 2015.

LEE, V. E.; BRYK, A. S.; SMITH, J. The organization of effective secondary schools. In: DARLING-HAMMOND, L. Review of Research in Education, Washington, DC, American Educational Research Association, p. 171-267, 1993.

LEE, V.; FRANCO, C.; ALBERNAZ, A. Quality and equality in Brazilian secondary schools: a multilevel cross-national school effects study. Annual Meeting of the American Educational Research Association, San Diego, 2004.

MACHADO SOARES, T. Influência do professor e do ambiente em sala de aula sobre a proficiência alcançada pelos alunos avaliados no Simave-2002, 2004.

MELLA, O. (Org.). Qualitative study of schools with outstanding results in seven Latin American countries. Santiago, Chile: Unesco, Latin American Laboratory for Assessment of the Quality of Education, 2002.

MEURET, D. Établissement scolaires: ce qui fait la différence. L'Année Sociologique, Paris, v. 50, n. 2, p. 545-556, 2000.

Organização para a Cooperação e Desenvolvimento Econômico. Résultats du Pisa 2009. Surmonter le milieu social: l'égalité des chances et l'équité du rendement de l'apprentissage, 2. Paris: OCDE. 2011.

PAUL, J. J.; BARBOSA, M. L. A qualidade dos professores como fator de eficácia escolar. REICE - Revista Electrónica Iberoamericana sobre Calidad, Eficacia y Cambio en Educación, v. 5, n. 5e, 2007.

PHILLIPS, D. Learning from elsewhere in education: some perennial problems revisited with reference to British interest in Germany. Comparative Education, v. 36, n. 3, p. 297-307, 2000.
RACZYNSKI, D.; MUÑOZ, G. Efectividad escolar y cambio educativo en condiciones de pobreza en Chile. Santiago de Chile: Ministerio de Educación, 2005.

RUTTER, M. Fifteen thousand hours: secondary schools and their effects on children. Cambridge: Harvard University Press, 1979.

SAMMONS, P.; HILLMAN, J.; MORTIMORE, P. Key Characteristics of effective schools: a review of school effectiveness research. London: Office for Standards in Education [OFSTED], 1995.

SÁTYRO, N.; SOARES, S. A infraestrutura das escolas brasileiras de ensino fundamental: um estudo com base nos censos escolares de 1997 a 2005. Brasília: Ipea, 2007. (Textos para Discussão, 1267).

SAUVY, A.; GIRARD, A. Les diverses classes sociales devant l'enseignement. Population, 2. Reprisin INED (1970), Population et l'enseignement. Paris: PUF, 1965. p. 233-260.

SCARTEZINI, R. A.; VIANA, T. de C. O efeito professor e sua transmissibilidade. In: COLÓQUIO DO LEPSI IP/FE-USP, 2010, São Paulo. Anais... São Paulo: USP, 2010. Disponível em: <http://www.proceedings.scielo.br/scielo.php?script=sci arttext\&pid=MSC0000000032010000100058\&lng=pt\&nrm= abn>. Acesso em: 30 set. 2013.

SCHEERENS, J. Improving school effectiveness. Paris: Unesco, International Institute for Educational Planning, 2000.

SCHEERENS, J.; BOSKER, R. The foundations of educational effectiveness. Oxford: Pergamon, 1997.

SCHIEFELBEIN, E.; SIMMONS, J. Os determinantes do desempenho escolar: uma revisão de pesquisas nos países em desenvolvimento. Cadernos de Pesquisa, São Paulo, n. 35, p. 53-72, nov. 1980 .

SOARES, J. F. Qualidade e eqüidade na educação básica brasileira: a evidência do SAEB-2001. Archivos Analíticos de Políticas Educativas, v. 12, n. 38, 2004. Disponível em: $<$ http://epaa.asu.edu/epaa/v12n38>. Acesso em: 21 maio 2012.

SOARES, S.; RAZO, R.; FARIÑAS, M. Perfil estatístico da educação rural: origem socioeconômica desfavorecida, insumos escolares deficientes e resultados inaceitáveis. In: BOF, Alvana Maria (Org.). A educação no Brasil rural. Brasília: Inep, 2006, p. 47-68.

SOARES, J. F.; ALVES, M. T. Desigualdades Raciais no Sistema Brasileiro de Educação Básica. Educação e Pesquisa, São Paulo, v. 29, p.147-165, 2003.

SOARES, J. F.; CÉSAR, C. C.; MAMBRINI, J. Determinantes de desempenho dos alunos do ensino básico brasileiro: evidências do SAEB de 1997. In: FRANCO, C. (Org.). Avaliação, ciclos e promoção na educação. Porto Alegre: Artmed, 2001. p. 121-153.

SOARES NETO, J. J. JESUS, G. R.; KARINO, C. A.; ANDRADE, D. F. Uma escala para medir a infraestrutura escolar. Est. Aval. Educ., São Paulo, v. 24, n. 54, p. 78-99, jan.-abr. 2013.

SOARES, J. F.; MAMBRINI, J.; PEREIRA, L. R.; ALVES, M. T. G. Fatores associados ao desempenho em língua portuguesa $\mathrm{e}$ matemática: evidência do SAEB - 2001. Minas Gerais, UFMG, 2001. 
THURLER, M. G. Inovar no interior da escola. Porto Alegre: Artmed, 2001.

WILLMS, J. D. Monitoring school performance. Washington, D.C.: The Falmer Press, 1992.

YIN, R. K. Aplications of case study research. Thousand Oaks: SAGE Publications, 1993.
Estudo de caso - planejamento e métodos. 3. ed. Porto Alegre: Bookman, 2005.

Recebido em 10-03-2015.

Aprovado em 15-01-2016. 